\title{
The Influence of Obesity on the Association of Obstructive Sleep Apnea and Atrial Fibrillation
}

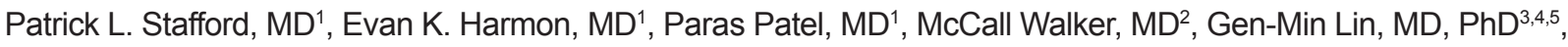 \\ Seung-Jung Park, MD, $\mathrm{PhD}^{6}$, Neal A. Chatterjee, $\mathrm{MD}^{7}$, Nishaki K. Mehta, $\mathrm{MD}^{8}$, \\ Sula Mazimba, $\mathrm{MD}^{1}$, Kenneth Bilchick, $\mathrm{MD}^{1}$, Younghoon Kwon, $\mathrm{MD}^{7}$ \\ ${ }^{1}$ Department of Medicine, University of Virginia, Charlottesville, VA, USA \\ ${ }^{2}$ Department of Medicine, University of Texas-Southwestern, Dallas, TX, USA \\ ${ }^{3}$ Department of Preventative Medicine, Northwestern University, Chicago, IL, USA \\ ${ }^{4}$ Department of Medicine, Hualien Armed Forces General Hospital, Hualien, Taiwan \\ ${ }^{5}$ Department of Medicine, Tri-Service General Hospital, National Defense Medical Center, Taipei, Taiwan \\ ${ }^{6}$ Department of Medicine, Heart Vascular Stroke Institute, Samsung Medical Center, Sungkyunkwan University School of Medicine, Seoul, Korea \\ ${ }^{7}$ Department of Medicine, University of Washington, Seattle, WA, USA \\ ${ }^{8}$ Department of Medicine, William Beaumont Hospital, Royal Oak, MI, USA
}

\author{
Received: January 25, 2021 \\ Revised: January 29, 2021 \\ Accepted: May 28, 2021 \\ Correspondence \\ Younghoon Kwon, MD \\ Internal Medicine, \\ University of Washington Medical Center, \\ Harborview Medical Center, \\ 325 9th Avenue, Box 359748, \\ Seattle, WA 98104-2499, USA \\ Tel +206-744-5853 \\ Fax +206-744-2224 \\ E-mail yhkwon@uw.edu \\ ORCID \\ Patrick L. Stafford \\ https://orcid.org/0000-0002-8686-5077 \\ Evan K. Harmon \\ https://orcid.org/0000-0002-0416-1544 \\ Gen-Min Lin \\ https://orcid.org/0000-0002-5509-1056 \\ Seung-Jung Park \\ https://orcid.org/0000-0003-3288-0594 \\ Neal A. Chatterjee \\ https://orcid.org/0000-0002-8290-127X
}

@ This is an Open Access article distributed under the terms of the Creative Commons Attribution Non-Commercial License (https://creativecommons.org/licenses/by-nc/4.0) which permits unrestricted non-commercial use, distribution, and reproduction in any medium, provided the original work is properly cited.
Background and Objective The association between obstructive sleep apnea (OSA) and atrial fibrillation (AF) has been closely studied. However, obesity is a powerful confounder in the causal relationship between OSA and cardiovascular disease. The contribution of obesity in the relationship between OSA and AF remains unclear.

Methods We recruited 457 consecutive patients equally with and without AF who underwent clinically indicated diagnostic polysomnography at a single academic sleep center. Multivariable logistic regression adjusting for age, sex, hypertension, and heart failure was performed to study the independent association between OSA and AF stratified by obesity.

Results A total of 457 patients (male: $56.2 \%$, mean age $63.1 \pm 13.3$ years) was included. OSA prevalence was similar between those with and without $\mathrm{AF}$ ( $52.6 \%$ vs. $47.4 \%$, respectively; $\mathrm{p}=0.24$ ). In multivariable analysis, no association was found between AF and OSA regardless of obesity status. When severe OSA (vs. non-severe OSA) was modeled as a dependent variable, AF was associated with a higher likelihood of severe OSA in non-obese patients [odds ratio (OR): 2.29, 95\% confidence interval (CI): 1.23-4.35, p = 0.01], but not in obese patients (OR: 0.95, 95\% CI: 0.48-1.90, p = 0.89).

Conclusions The association of OSA with AF was present only in the non-obese and was limited to severe OSA patients. In contrast, no association was found in obese patients. The association between OSA and AF is partly dependent on the body habitus.

Sleep Med Res 2021;12(1):50-56

Key Words Obesity, Obstructive sleep apnea, Atrial fibrillation.

\section{INTRODUCTION}

Atrial fibrillation (AF) is the most common chronic cardiac dysrhythmia, and is associated with poor quality of life as well as increased cardiovascular morbidity and mortality [1]. Obstructive sleep apnea (OSA) is the most common form of sleep-disordered breathing, and has previously been associated with adverse cardiovascular outcomes, including hypertension, ischemic heart disease, heart failure (HF), arrhythmias, and sudden cardiac death [2-10]. OSA is prevalent in the general adult population affecting at least $10-20 \%$ for males and $3-10 \%$ for females [11]. An increasing number of studies have implicated OSA as an important risk factor 
for AF [12-16]. However, delineating an independent association between OSA and AF is challenging, especially given their multiple shared risk factors, such as metabolic syndrome, age, obesity, and hypertension [17].

Of these mutual risk factors, obesity is particularly important as it is one of the most commonly shared risk factors for both OSA and AF. A clearer understanding of the relationship between these two conditions is particularly vital given that OSA and obesity are potentially modifiable risk factors for AF [18-20]. Notably, studies examining the association between OSA and AF have produced inconsistent outcomes, potentially due to differences in the distribution of obesity among study populations and/or overlooking the effect of obesity in their analyses [21-26]. From a clinical standpoint, determining whom to screen for OSA can be challenging in AF patients who have normal body habitus and otherwise without sleep related symptoms. Hence, we sought to investigate whether an association between OSA and AF differs by obesity diagnosis.

\section{METHODS}

\section{Subjects and Study Design}

We retrospectively recruited consecutive patients who were referred to an academic sleep medicine center and who then underwent diagnostic polysomnography (PSG) from April 1, 2013 through June 30, 2017. In all cases, the indication for PSG was for the evaluation of OSA. Inclusion criteria were that age was $\geq 18$ years in addition to having full and complete diagnostic data from PSG. All patients with complete PSG data were included in analysis. Those patients with continuous positive airway pressure (CPAP) titration or split night studies were not recruited for this study. Patients with primarily central sleep apnea, all of whom had AF, were not included $(\mathrm{n}=11)$.

To augment the number of AF patients in our analysis, we identified patients with AF (April 2013-December 2016) and subsequently selected an equal number of patients without AF (January-June 2017). In other words, these patients were selected in a 1:1 fashion based on AF status. Patient information such as demographics, medical comorbidities, medication prescriptions, and PSG data were acquired from the electronic medical record. Each patient's history was independently reviewed by a clinician for verification of data in order to identify discrepancies. AF was diagnosed by International Classification of Diseases-10 coding (I48.0, I48.1, I48.11, I48.19, I48.2, I48.20, I48.21, I48.91, Z86.79) in the electronic medical record. We then reviewed electrocardiograms and clinic notes to confirm the accuracy of AF diagnosis. The diagnosis of AF was not based on electrocardiograms obtained during the PSG. Age was stratified by older vs. younger, according to the median age of the cohort. Obesity was defined as body mass index $(\mathrm{BMI}) \geq 30 \mathrm{~kg} / \mathrm{m}^{2}$. As comorbid HF confounds the association of OSA and AF, effort was made to accurately determine HF status. HF was defined as either left ventricular ejection fraction $<40 \%$ or preserved left ventricular ejection fraction with a HF exacerbation as a primary or secondary admission diagnosis. We subsequently confirmed this HF diagnosis by clinician chart review. This study was approved by the University of Virginia Institutional Review Board (IRB 19394).

\section{Sleep Study Data}

Overnight PSG was scored under the guidelines put forth by the American Academy of Sleep Medicine [27]. PSGs were first scored by a certified PSG technologist followed by verification by a certified sleep physician. PSG data were managed with Embla Sandman Elite software (Natus Medical Inc., Pleasanton, CA, USA). A standard thermocouple system was used to measure apnea and hypopnea episodes. As per guidelines, apnea was defined as a nasal pressure flow signal reduction of $>90 \%$ of the baseline signal that lasted for at least 10 seconds. Hypopnea events were defined as pressure flow signal reductions of $>30 \%$ of the baseline that lasted for at least 10 seconds with a $\geq 4 \%$ oxygen saturation reduction. The apnea-hypopnea index (AHI) was defined as the number of apnea and hypopnea events divided by the total sleep time. AHI was presented as number of events per hour. OSA was diagnosed with an AHI $\geq 15 / \mathrm{hr}$ and severe OSA was diagnosed for $\mathrm{AHI} \geq 30 / \mathrm{hr}$.

\section{Statistical Analysis}

Baseline characteristics were described for the cohort and then stratified by obesity. Categorical variables were reported as frequencies and percentages and analyzed using the chi-squared test. Continuous data were presented as mean and standard deviation (SD) and analyzed by the t-test. Multivariable logistic regression stratified by obesity was performed to examine the association between $\mathrm{AF}$ as the independent variable to OSA or severe OSA as the dependent variable. This design was motivated by the more clinical context where determining whom to screen for OSA in patients with AF is a practical issue (i.e., designating OSA as an outcome in the model) compared to vice-versa. The model was then adjusted for age, male sex, hypertension, obesity, and HF. Analyses were then repeated excluding HF patients. P-values of $<0.05$ and alpha values of $<0.05$ were statistically significant. These analyses were performed using Statistical Analysis System (SAS) v9.2 (SAS Institute Inc., Cary, NC, USA).

\section{RESULTS}

Study population demographics and clinical data are presented in Table 1. Four hundred and fifty-seven patients were included, in which 228 (50\%) had AF based on the inclusion of patients in a 1:1 fashion by study design. Of these AF patients, $182(80 \%)$ had paroxysmal AF, while $46(20 \%)$ had persistent or permanent AF. The mean (SD) age of the cohort was 63.1 (13.3) years. The 
Table 1. Patient characteristics stratified by obesity

\begin{tabular}{lcccc}
\hline \multicolumn{1}{c}{ Characteristic } & $\begin{array}{c}\text { Overall } \\
(\mathrm{n}=457)\end{array}$ & $\begin{array}{c}\text { Non-obese patients } \\
(\mathrm{n}=241)\end{array}$ & $\begin{array}{c}\text { Obese patients } \\
(\mathrm{n}=216)\end{array}$ & p-value \\
\hline Age (years) & $63.1 \pm 13.3$ & $65.1 \pm 13.3$ & $60.8 \pm 13.1$ & $<0.0001$ \\
Male sex & $257(56.2)$ & $160(66.4)$ & $97(44.9)$ & $<0.0001$ \\
Body mass index $\left(\mathrm{kg} / \mathrm{m}^{2}\right)$ & $32.2 \pm 8.2$ & $26.5 \pm 2.6$ & $38.6 \pm 7.5$ & $<0.0001$ \\
Diabetes & $175(38.3)$ & $63(26.1)$ & $112(51.9)$ & $<0.0001$ \\
Hypertension & $272(59.5)$ & $146(60.6)$ & $126(58.3)$ & 0.547 \\
Stroke/transient ischemic attack & $43(9.40)$ & $16(6.64)$ & $27(12.5)$ & 0.148 \\
Congestive heart failure & $54(11.8)$ & $24(9.96)$ & $30(13.9)$ & 0.246 \\
Medications & & & & $<0(27.7)$ \\
$\quad$ Beta blocker & $179(39.2)$ & $119(49.4)$ & $3(1.39)$ & $<0.0001$ \\
Calcium channel blocker & $49(10.7)$ & $46(19.1)$ & $20(9.26)$ & 0.0001 \\
Digoxin & $29(6.4)$ & $9(3.73)$ & $53(24.5)$ & 0.011 \\
Anti-arrhythmic & $89(19.5)$ & $36(14.9)$ & \\
\hline Data & & & $<$ \\
\hline
\end{tabular}

Data are presented as $\mathrm{n}(\%)$ or mean \pm standard deviation.

Table 2. AF stratified by OSA presence and severity

\begin{tabular}{lcccc}
\hline Characteristic & No OSA $(\mathrm{AHI}<15 / \mathrm{hr})$ & All OSA $(\mathrm{AHI}>15 / \mathrm{hr})$ & $\begin{array}{c}\text { Less severe OSA } \\
(15<\mathrm{AHI} \leq 30 / \mathrm{hr})\end{array}$ & $\begin{array}{c}\text { Severe OSA } \\
(\mathrm{AHI}>30 / \mathrm{hr})\end{array}$ \\
\hline AF & $98(21.4)$ & $131(28.6)$ & $57(12.5)$ & $74(16.2)$ \\
No AF & $110(24.1)$ & $118(25.8)$ & $65(14.2)$ & $53(11.6)$ \\
\hline
\end{tabular}

Data are presented as $\mathrm{n}(\%)$.

OSA: obstructive sleep apnea, AHI: apnea-hypopnea index, AF: atrial fibrillation.

overall mean BMI was $32.2(8.2) \mathrm{kg} / \mathrm{m}^{2}$, with 216 (47.3\%) of the patients being obese. The BMI was similar between those with and without AF [32.1 (7.9) kg/m² and $32.3(8.5) \mathrm{kg} / \mathrm{m}^{2}$, respectively; $\mathrm{p}=0.82$ ]. Overall, the obese patients tended to be younger, diabetic, and be less male predominant when compared to the non-obese group. More than half of the cohort had OSA [ $\mathrm{n}=$ $249(54.5 \%)$ ], with more than a quarter of patients having severe OSA $[n=127(27.8 \%)]$. The prevalence of either OSA or severe OSA (i.e., any AHI > 15/hr) was similar between those with and without $\operatorname{AF}(52.6 \%$ vs. $47.4 \%$, respectively; $\mathrm{p}=0.24)$. Stratification of the patients with and without AF by OSA presence and severity is included in Table 2. In non-obese patients, severe OSA was more prevalent in patients with $\mathrm{AF}$ compared with those without. However, in obese patients, there was no difference in the prevalence of severe OSA between patients with and without AF (Fig. 1). Overall, the mean AHI was $25.0 \pm 23.9 / \mathrm{hr}$ and the mean oxygen saturation during PSG was $94.1 \% \pm 2.4 \%$. Male sex was associated with higher AHI. PSG characteristics were similar between the obese and non-obese groups (Table 3).

In multivariable analysis, no association was found between AF and any OSA regardless of obesity status (Supplementary Tables 1 and 2 in the online-only Data Supplement). When severe OSA (vs. non-severe OSA) was modeled as a dependent variable, AF was associated with a higher likelihood of severe OSA in non-obese patients [odds ratio (OR) 2.29, 95\% confi-

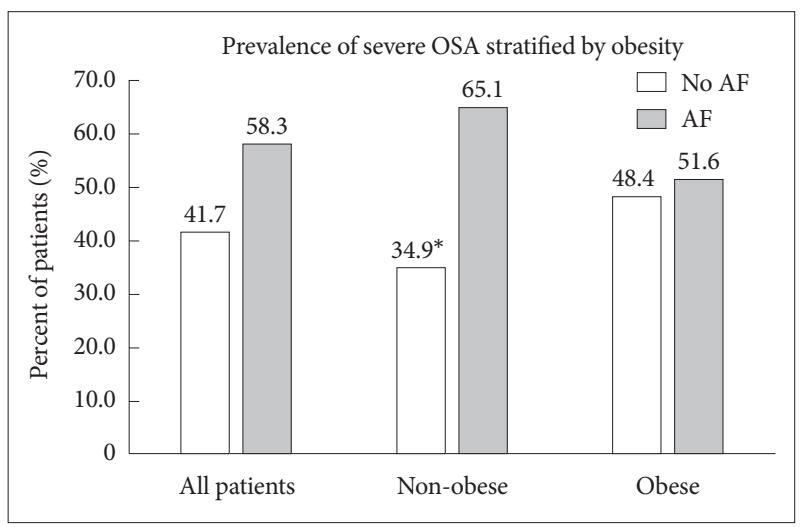

Fig. 1. Comparison of the prevalence of severe OSA between all patients, non-obese patients, and obese patients. There was no difference in the prevalence of severe OSA was observed in all patients and obese patients. In non-obese patients, there was a statistically significant higher prevalence of severe OSA in patients with AF than those without. ${ }^{*} p=0.011$. OSA: obstructive sleep apnea, AF: atrial fibrillation.

dence interval (CI) 1.23-4.35, $\mathrm{p}=0.01$ ], but not in obese patients (OR 0.95, 95\% CI 0.48-1.90, $\mathrm{p}=0.89$ ) (Tables 4 and 5). When excluding those patients with HF, this same pattern of association persisted (Supplementary Tables 3 and 4 in the online-only Data Supplement). 
Table 3. Sleep study characteristics stratified by obesity

\begin{tabular}{|c|c|c|c|c|}
\hline Characteristic & $\begin{array}{l}\text { Overall } \\
(\mathrm{n}=457)\end{array}$ & $\begin{array}{c}\text { Non-obese patients } \\
(\mathrm{n}=241)\end{array}$ & $\begin{array}{l}\text { Obese patients } \\
\quad(\mathrm{n}=216)\end{array}$ & p-value \\
\hline Total sleep time (min) & $284.0(119.8)$ & $279.3(122.6)$ & $289.1(116.7)$ & 0.384 \\
\hline Sleep efficiency (\%) & $70.6(18.4)$ & $69.6(18.6)$ & $71.7(18.2)$ & 0.231 \\
\hline N3 slow wave sleep quantity (min) & $11.2(13.7)$ & $10.7(12.8)$ & $11.6(14.7)$ & 0.478 \\
\hline Arousal index $(1 / \mathrm{hr})$ & $30.1(27.1)$ & $30.4(25.2)$ & $29.7(29.1)$ & 0.810 \\
\hline Respiratory arousal index (1/hr) & $21.7(24.0)$ & $20.8(21.4)$ & $21.5(26.7)$ & 0.791 \\
\hline Periodic limb movement with arousal (1/hr) & $2.7(11.9)$ & $3.1(12.4)$ & $2.4(10.4)$ & 0.427 \\
\hline Spontaneous arousal index $(1 / \mathrm{hr})$ & $6.25(7.93)$ & $6.38(6.66)$ & $6.10(9.15)$ & 0.707 \\
\hline Apnea-hypopnea index $(1 / \mathrm{hr})$ & $25.0(23.9)$ & $24.0(21.2)$ & $26.0(22.5)$ & 0.390 \\
\hline Obstructive sleep apnea index $(1 / \mathrm{hr})$ & $18.8(35.4)$ & $17.1(19.1)$ & $20.6(47.3)$ & 0.284 \\
\hline Central sleep apnea index $(1 / \mathrm{hr})$ & $1.55(5.24)$ & $1.74(5.89)$ & $1.34(4.41)$ & 0.402 \\
\hline Mean oxygen saturation (\%) & $94.1(2.3)$ & $94.1(2.3)$ & $93.9(2.6)$ & 0.370 \\
\hline
\end{tabular}

Data are presented as mean \pm standard deviation.

Table 4. Multivariable analyses of predictors of severe obstructive sleep apnea in non-obese patients

\begin{tabular}{lcc}
\hline Characteristic & OR $(95 \% \mathrm{CI})$ & $\mathrm{p}$-value \\
\hline Age & $1.02(0.54-1.94)$ & 0.958 \\
Male sex & $1.38(0.73-2.70)$ & 0.330 \\
Hypertension & $1.32(0.70-2.51)$ & 0.399 \\
Atrial fibrillation & $2.27(1.21-4.33)$ & 0.011 \\
Heart failure & $0.96(0.36-2.42)$ & 0.936 \\
\hline
\end{tabular}

OR: odds ratio, CI: confidence interval.

Table 5. Multivariable analyses of predictors of severe obstructive sleep apnea in obese patients

\begin{tabular}{lcc}
\hline Characteristic & OR $(95 \% \mathrm{CI})$ & $\mathrm{p}$-value \\
\hline Age & $1.66(0.89-3.10)$ & 0.112 \\
Male sex & $2.07(1.13-3.81)$ & 0.019 \\
Hypertension & $0.80(0.40-1.57)$ & 0.507 \\
Atrial fibrillation & $0.81(0.40-1.60)$ & 0.539 \\
Heart failure & $1.63(0.69-3.79)$ & 0.251 \\
\hline
\end{tabular}

OR: odds ratio, CI: confidence interval.

\section{DISCUSSION}

The intent of this study was to examine whether the association of OSA and AF differs by obesity status. In this cohort of sleep clinic patients undergoing PSG, we found that AF was associated with severe OSA, but such an association existed only in the non-obese patients. Specifically, non-obese patients with AF were about two times more likely to have severe OSA. This finding was independent of the confounding factors of age, sex, and HF. This suggests that the association between OSA and AF may be body-habitus dependent. These results do not suggest that obese patients with AF are not at high risk of OSA. In that these patients are obese and by virtue of other comorbidities and factors, they are still at high risk of AF. These results provide an important additional insight into the relationship between obesity, OSA, and AF.

Obesity and OSA share multiple pathophysiological mechanisms, including insulin resistance, hyperleptinemia, endothelial dysfunction, and sympathetic overactivity [28]. They are also associated with the incidence and progression of AF $[29,30]$. OSA modifies AF via several related mechanisms, with increased sympathetic and vagal tone, hypoxia, and changes in intrathoracic pressure all contributing to AF burden. Therefore, a complex interplay exists between obesity, OSA, and AF [31,32] (Fig. 2). Properly accounting and correcting for the confounding effect of obesity is important in better understanding the relationship between OSA and AF. While it can be addressed by statistical adjustment, residual confounding may persist [33]. In this study, we attempted to address this by stratifying the cohort into two groups by obesity status.

As anticipated, OSA was highly prevalent in this clinic cohort. When using a more conservative OSA definition, over half of the cohort had OSA and about one-fourth of the cohort had severe OSA. Our hypothesis was that the association of OSA and AF would only exist in non-obese patients as the confounding effect of obesity would be minimized. The results support this assumption, but we found that the association also appears to be limited to severe OSA.

This partly suggests that patients with severe OSA may represent a distinct group from those with non-severe OSA, especially in terms of AF risk. This is consistent with findings from the Sleep Heart Health Study, which established that incidence of nocturnal AF episodes was markedly higher in patients with severe OSA compared to those without OSA ( $4.8 \%$ vs. $0.9 \%, \mathrm{p}=$ 0.003) [15]. However, since the average BMI was $29 \mathrm{~kg} / \mathrm{m}^{2}$ in that study, which is similar to the cut off value used in our study to 


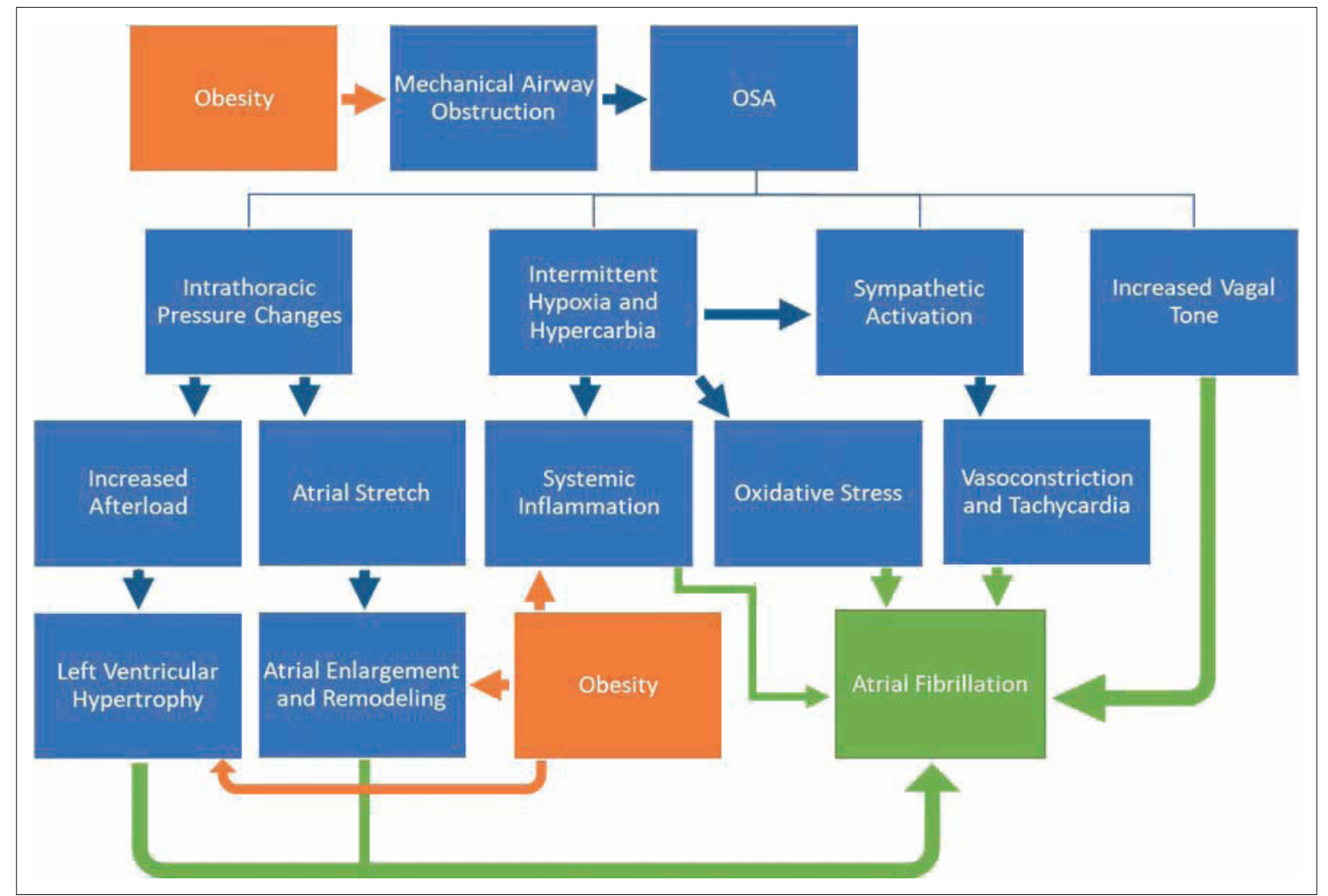

Fig. 2. Proposed complex pathophysiology connecting obesity, OSA, and atrial fibrillation. OSA: obstructive sleep apnea.

determine the non-obese group vs. obese group and the results by body habitus was not shown, direct comparison with our study is not feasible. Cadby et al. [34] followed 6841 sleep clinic patients a median 11.9 years and determined that OSA (defined as AHI $\geq 5 / \mathrm{hr}$ ) was an independent predictor of hospital admission for incident AF [hazard ratio (HR) 1.55, 95\% CI 1.21-2.00]. Those with severe OSA (defined as AHI $\geq 30 / \mathrm{hr}$ ) had even a higher incidence of AF (HR 1.73, 95\% CI 1.29-2.33). As such, the association of OSA and AF may be limited to severe OSA.

The findings of our current study are consistent with the Stevenson et al. [35] study, which prospectively enrolled 90 patients with paroxysmal or persistent AF matched to 45 controls who both subsequently underwent diagnostic PSG. The prevalence of OSA (AHI > 15/hr) was greater in the AF group with subsequent multivariable analysis demonstrating an association between the two (OR 3.04). The patient population was largely non-obese, with a weighted mean BMI of approximately 27.5 $\mathrm{kg} / \mathrm{m}^{2}$ and was without traditional risk factors for OSA. Yet, we are unable to directly cross examine our findings in majority of other studies as, despite controlling for BMI, the interaction of OSA and body habitus in the relationship with AF has not typically been considered in their analyses. Lin et al. [24] in the Multi-Ethnic Study of Atherosclerosis demonstrated conflicting results that physician diagnosed OSA was associated with incident AF people with obesity $\left(\mathrm{BMI}>30 \mathrm{~kg} / \mathrm{m}^{2}\right)(\mathrm{OR} 2.73,95 \%$ CI 1.33-5.60), but not in people without obesity. However, nonobesity was not associated with incident AF (OR 1.04, 95\% CI
0.41-2.59). The reason might be partly due to the fact that they used the physician-diagnosed OSA rather than screening entire cohort with PSG. Their results were also obtained from a multiethnic general population with relatively low risk for OSA and might not be appropriately translated to our results using clinicbased participants with multiple OSA risk factors.

Still, the absence of significant association between OSA and AF may have resulted from additional unmeasured or unidentified confounding variables may have nullified or altered the association in the obese. Most of the patients with OSA or severe OSA did not have AF, but a significant portion of patients with AF had OSA or severe OSA.

There is some suggestion that non-obese patients with OSA have a different clinical phenotype than the obese population [36]. Non-obese patients seem to have a lower threshold for respiratory arousal, leading to a higher measured AHI, and they also seem to have higher rates of altered craniofacial anatomy, including a larger soft palate and smaller anterior-posterior dimensions of the naso- and oropharynx [37]. This finding may be particularly pertinent to Asian populations whose body habitus is typically non-obese yet has a higher prevalence of OSA. Our study findings may prompt a clinician to consider the risk of OSA even among non-obese AF patients. Further, this may support the notion that screening for OSA by diagnostic PSG may be warranted in all AF patients, regardless of body habitus or perceived risk. With the more widespread use of home PSG and improved methods of AF detection, we anticipate that there 
would be more opportunities to further verify our findings and examine the implications of this finding in the context of future outcomes.

A strength of our study includes the individual review of each chart by a clinician for confirmation of AF status, clinically-relevant HF, and medication prescriptions. This increases the fidelity of the extracted data. Several limitations need to be considered in our study. Our study suffers from selection bias given that only referred patients were included. However, this bias exists for both cases and controls. This study is also unable to infer any causal relationship between OSA and AF in non-obese patients, despite finding an association between the two. Approximately one-third of those with AF are asymptomatic, suggesting that some patients within the no-AF cohort likely had subclinical AF [13]. The true burden of AF is difficult to assess without repeated and/or continuous rhythm monitoring. It is also possible that the degree of AF burden and severity of OSA have an interaction that was not feasible to investigate in this study. Data regarding the use of CPAP prior to the diagnostic PSG in those patients undergoing re-evaluation of their OSA was not available in our study. Despite the lack of evidence supporting the effect of CPAP on the primary prevention of AF, the results in our study may have been affected by CPAP therapy, which was not considered in our study. The AHI criteria (AHI 15) used in this study to define OSA may have been overly strict. However, such cut off value is frequently adopted in both clinical and research settings [38].

\section{Conclusion}

In conclusion, in patients with high risk AF, the independent association of AF with OSA was present only in the non-obese, and such an association was limited to patients with severe OSA. In contrast, no association between AF and OSA was found in obese patients regardless of the OSA severity. This suggests that the association between AF and OSA is partly dependent on body habitus.

\section{Supplementary Materials}

The online-only Data Supplement is available with this article at https://doi.org/10.17241/smr.2021.00857.

\section{Acknowledgments}

This work was partly supported by the George Beller Award (Heart and Vascular Institute of University of Virginia) and NIH under grant R21HL140432 and R21HL150502 (YK).

\section{Conflicts of Interest}

The authors have no financial conflicts of interest.

\section{Authors' Contribution}

Conceptualization: Stafford PL, Kwon Y. Data curation: Stafford PL, Harmon EK, Patel P, Walker M. Formal analysis: Stafford PL, Kwon Y, Bilchick K. Funding acquisition: Kwon Y. Investigation: Stafford PL, Kwon Y, Harmon EK, Patel P, Walker M, Bilchick K. Methodology: Stafford PL, Kwon Y, Mazimba S. Project administration: Kwon Y. Resources: Kwon Y, Mazimba S, Bilchick K. Software: Kwon Y, Mazimba S, Bilchick
K. Supervision: Kwon Y, Mazimba S, Bilchick K, Mehta NK. Validation: Lin GM, Park SJ, Chatterjee NA, Mehta NK. Visualization: Stafford PL, Kwon Y. Writing_original draft: Stafford PL, Kwon Y. Writing-review \& editing: all authors.

\section{REFERENCES}

1. Go AS, Hylek EM, Phillips KA, Chang Y, Henault LE, Selby JV, et al. Prevalence of diagnosed atrial fibrillation in adults: national implications for rhythm management and stroke prevention: the AnTicoagulation and Risk Factors in Atrial Fibrillation (ATRIA) Study. JAMA 2001;285:2370-5.

2. Floras JS. Sleep apnea and cardiovascular disease: an enigmatic risk factor. Circ Res 2018;122:1741-64.

3. Raghuram A, Clay R, Kumbam A, Tereshchenko LG, Khan A. A systematic review of the association between obstructive sleep apnea and ventricular arrhythmias. J Clin Sleep Med 2014;10:1155-60.

4. Chadda KR, Fazmin IT, Ahmad S, Valli H, Edling CE, Huang CL, et al. Arrhythmogenic mechanisms of obstructive sleep apnea in heart failure patients. Sleep 2018;41:zsy136.

5. Gami AS, Olson EJ, Shen WK, Wright RS, Ballman KV, Hodge DO, et al. Obstructive sleep apnea and the risk of sudden cardiac death: a longitudinal study of 10,701 adults. J Am Coll Cardiol 2013;62:610-6.

6. Gottlieb DJ, Yenokyan G, Newman AB, O'Connor GT, Punjabi NM, Quan SF, et al. Prospective study of obstructive sleep apnea and incident coronary heart disease and heart failure: the sleep heart health study. Circulation 2010;122:352-60.

7. Walker M, Patel P, Kwon O, Koene RJ, Duprez DA, Kwon Y. Withdrawal notice: atrial fibrillation and hypertension: "Quo Vadis". Curr Hypertens Rev 2019 May 2 [Epub]. https://doi.org/10.2174/157340211 5666190502142824 .

8. Blackwell JN, Walker M, Stafford P, Estrada S, Adabag S, Kwon Y. Sleep apnea and sudden cardiac death. Circ Rep 2019;1:568-74.

9. Kwon Y, Koene RJ, Kwon O, Kealhofer JV, Adabag S, Duval S. Effect of sleep-disordered breathing on appropriate implantable cardioverterdefibrillator therapy in patients with heart failure: a systematic review and meta-analysis. Circ Arrhythm Electrophysiol 2017;10:e004609.

10. Kwon Y, Logan J, Pusalavidyasagar S, Kasai T, Cheong CS, Lee CH. Sleep apnea and heart. Sleep Med Res 2019;10:67-74.

11. Peppard PE, Young T, Barnet JH, Palta M, Hagen EW, Hla KM. Increased prevalence of sleep-disordered breathing in adults. Am J Epidemiol 2013;177:1006-14.

12. Tedrow UB, Conen D, Ridker PM, Cook NR, Koplan BA, Manson JE, et al. The long- and short-term impact of elevated body mass index on the risk of new atrial fibrillation the WHS (women's health study). $J$ Am Coll Cardiol 2010;55:2319-27.

13. Foy AJ, Mandrola J, Liu G, Naccarelli GV. Relation of obesity to newonset atrial fibrillation and atrial flutter in adults. Am J Cardiol 2018; 121:1072-5.

14. Huxley RR, Lopez FL, Folsom AR, Agarwal SK, Loehr LR, Soliman EZ, et al. Absolute and attributable risks of atrial fibrillation in relation to optimal and borderline risk factors: the Atherosclerosis Risk in Communities (ARIC) study. Circulation 2011;123:1501-8.

15. Mehra R, Benjamin EJ, Shahar E, Gottlieb DJ, Nawabit R, Kirchner $\mathrm{HL}$, et al. Association of nocturnal arrhythmias with sleep-disordered breathing: The Sleep Heart Health Study. Am J Respir Crit Care Med 2006;173:910-6

16. Holmqvist F, Guan N, Zhu Z, Kowey PR, Allen LA, Fonarow GC, et al. Impact of obstructive sleep apnea and continuous positive airway pressure therapy on outcomes in patients with atrial fibrillation-results from the Outcomes Registry for Better Informed Treatment of Atrial Fibrillation (ORBIT-AF). Am Heart J 2015;169:647-54.e2.

17. Kwon Y, Koene RJ, Johnson AR, Lin GM, Ferguson JD. Sleep, sleep apnea and atrial fibrillation: questions and answers. Sleep Med Rev 2018;39:134-42. 
18. Staerk L, Sherer JA, Ko D, Benjamin EJ, Helm RH. Atrial fibrillation: epidemiology, pathophysiology, and clinical outcomes. Circ Res 2017; 120:1501-17.

19. Zhang L, Hou Y, Po SS. Obstructive sleep apnoea and atrial fibrillation. Arrhythm Electrophysiol Rev 2015;4:14-8.

20. Berkovitch A, Kivity S, Klempfner R, Segev S, Milwidsky A, Erez A, et al. Body mass index and the risk of new-onset atrial fibrillation in middle-aged adults. Am Heart J 2016;173:41-8.

21. Kwon Y, Gharib SA, Biggs ML, Jacobs DR Jr, Alonso A, Duprez D, et al. Association of sleep characteristics with atrial fibrillation: the MultiEthnic Study of Atherosclerosis. Thorax 2015;70:873-9.

22. Arzt M, Woehrle H, Oldenburg O, Graml A, Suling A, Erdmann E, et al. Prevalence and predictors of sleep-disordered breathing in patients with stable chronic heart failure: the SchlaHF registry. JACC Heart Fail 2016;4:116-25.

23. Leung RS, Huber MA, Rogge T, Maimon N, Chiu KL, Bradley TD. Association between atrial fibrillation and central sleep apnea. Sleep 2005; 28:1543-6.

24. Lin GM, Colangelo LA, Lloyd-Jones DM, Redline S, Yeboah J, Heckbert SR, et al. Association of sleep apnea and snoring with incident atrial fibrillation in the multi-ethnic study of atherosclerosis. Am J Epidemiol 2015;182:49-57.

25. Frost L, Hune LJ, Vestergaard P. Overweight and obesity as risk factors for atrial fibrillation or flutter: the Danish Diet, Cancer, and Health Study. Am J Med 2005;118:489-95.

26. Porthan KM, Melin JH, Kupila JT, Venho KK, Partinen MM. Prevalence of sleep apnea syndrome in lone atrial fibrillation: a case-control study. Chest 2004;125:879-85.

27. Berry RB, Budhiraja R, Gottlieb DJ, Gozal D, Iber C, Kapur VK, et al. Rules for scoring respiratory events in sleep: update of the 2007 AASM manual for the scoring of sleep and associated events: deliberations of the sleep apnea definitions task force of the American Academy of Sleep Medicine. J Clin Sleep Med 2012;8:597-619.

28. Gami AS, Caples SM, Somers VK. Obesity and obstructive sleep apnea. Endocrinol Metab Clin North Am 2003;32:869-94.
29. Vyas V, Lambiase P. Obesity and atrial fibrillation: epidemiology, pathophysiology and novel therapeutic opportunities. Arrhythm Electrophysiol Rev 2019;8:28-36.

30. Jehan S, Zizi F, Pandi-Perumal SR, Wall S, Auguste E, Myers AK, et al. Obstructive sleep apnea and obesity: implications for public health. Sleep Med Disord 2017;1:00019.

31. Arias MA, Sánchez AM, Alonso-Fernández A, García-Río F. Atrial fibrillation, obesity, and obstructive sleep apnea. Arch Intern Med 2007; 167:1552-3.

32. Chung MK, Foldvary-Schaefer N, Somers VK, Friedman PA, Wang PJ. Atrial fibrillation, sleep apnea and obesity. Nat Clin Pract Cardiovasc Med 2004;1:56-9.

33. Pourhoseingholi MA, Baghestani AR, Vahedi M. How to control confounding effects by statistical analysis. Gastroenterol Hepatol Bed Bench 2012;5:79-83.

34. Cadby G, McArdle N, Briffa T, Hillman DR, Simpson L, Knuiman M, et al. Severity of OSA is an independent predictor of incident atrial fibrillation hospitalization in a large sleep-clinic cohort. Chest 2015;148: 945-52.

35. Stevenson IH, Teichtahl H, Cunnington D, Ciavarella S, Gordon I, Kalman JM. Prevalence of sleep disordered breathing in paroxysmal and persistent atrial fibrillation patients with normal left ventricular function. Eur Heart J 2008;29:1662-9.

36. Gray EL, McKenzie DK, Eckert DJ. Obstructive sleep apnea without obesity is common and difficult to treat: evidence for a distinct pathophysiological phenotype. J Clin Sleep Med 2017;13:81-8.

37. Sakakibara H, Tong M, Matsushita K, Hirata M, Konishi Y, Suetsugu S. Cephalometric abnormalities in non-obese and obese patients with obstructive sleep apnoea. Eur Respir J 1999;13:403-10.

38. Tunis S, Shuren J, Spencer F, Chin J, Sheridan J. Decision memo for continuous positive airway pressure (CPAP) therapy for obstructive sleep apnea (OSA) (CAG-00093 N) [cited 2021 May 22]. Available from: https://www.cms.gov/medicare-coverage-database/details/nca-decision-memo.aspx?NCAId=19\&fromdb=true. 
Supplementary Table 1. Multivariable analyses of predictors of severe obstructive sleep apnea in non-obese patients

\begin{tabular}{lcc}
\hline \multicolumn{1}{c}{ Characteristic } & OR $(95 \% \mathrm{CI})$ & p-value \\
\hline Age & $1.76(1.01-3.10)$ & 0.048 \\
Male sex & $1.33(0.77-2.33)$ & 0.310 \\
Hypertension & $1.05(0.60-1.83)$ & 0.857 \\
Atrial fibrillation & $1.30(0.75-2.26)$ & 0.348 \\
Heart failure & $2.23(0.85-6.58)$ & 0.133 \\
\hline
\end{tabular}

OR: odds ratio, CI: confidence interval. 
Supplementary Table 2. Multivariable analyses of predictors of severe obstructive sleep apnea in obese patients

\begin{tabular}{lcc}
\hline \multicolumn{1}{c}{ Characteristic } & OR $(95 \% \mathrm{CI})$ & p-value \\
\hline Age & $1.08(0.60-1.94)$ & 0.794 \\
Male sex & $2.47(1.41-4.39)$ & 0.002 \\
Hypertension & $1.20(0.65-2.25)$ & 0.563 \\
Atrial fibrillation & $0.82(0.43-1.55)$ & 0.547 \\
Heart failure & $2.01(0.88-4.89)$ & 0.107 \\
\hline
\end{tabular}

OR: odds ratio, CI: confidence interval. 
Supplementary Table 3. Multivariable analyses of predictors of severe obstructive sleep apnea in non-obese patients (excluding heart failure patients)

\begin{tabular}{lcc}
\hline Characteristic & OR $(95 \%$ CI $)$ & p-value \\
\hline Age & $0.99(0.51-1.97)$ & 0.998 \\
Male sex & $1.22(0.63-2.41)$ & 0.568 \\
Hypertension & $1.41(0.73-2.83)$ & 0.316 \\
Atrial fibrillation & $2.19(1.16-4.20)$ & 0.017 \\
\hline
\end{tabular}

OR: odds ratio, CI: confidence interval. 
Supplementary Table 4. Multivariable analyses of predictors of severe obstructive sleep apnea in obese patients (excluding heart failure patients)

\begin{tabular}{lcc}
\hline Characteristic & OR $(95 \%$ CI $)$ & p-value \\
\hline Age & $1.55(0.80-3.05)$ & 0.202 \\
Male sex & $2.03(1.06-3.93)$ & 0.035 \\
Hypertension & $0.83(0.41-1.71)$ & 0.611 \\
Atrial fibrillation & $1.04(0.50-2.15)$ & 0.918 \\
\hline
\end{tabular}

OR: odds ratio, $\mathrm{CI}$ : confidence interval. 